\title{
PENERAPAN METODE KOOPERATIF TIPE TALKING STICK TERHADAP HASIL BELAJAR PAI
}

\author{
Haerudin \\ Fakultas Keguruan dan Ilmu Pendidikan \\ Universitas Buana Perjuangan Karawang \\ haerudin@ubpkarawang.ac.id
}

\begin{abstract}
This study aims to examine how much the effectiveness of the application of cooperative learning method of Talking Stick Type to the learning outcomes of Religious Education in SD Negeri I Plawad, in order to improve the learning outcomes in the elementary school, and to know how much student response to the application of cooperative learning model with Talking Stick model. This research was conducted with research subjects of V student of SD Negeri I Plawad karawang academic year 20017/2018. The research method used is class action method (PTK) consisting of 2 cycles, each cycle consists of 2 meetings. Data collection through pretest, posttes, observation, questionnaires, field notes, and interviews. From the results of this study, the researcher hopes to give contribution and benefit for all related parties, especially the school in order to improve the learning result especially in the field of PAI lesson generally for other lessons, so it can be useful also for other schools in general.
\end{abstract}

\section{Keywords: Learning Talking Stick, Learning Outcomes.}

\begin{abstract}
Abstrak: Penelitian ini bertujuan untuk menelaah seberapa besar efektifitas penerapan pembelajaran metode cooperative learning Tipe Talking Stick terhadap hasil belajar Pendidikan Agama di SD Negeri I Plawad, guna meningkatkan hasil belajar di SD tersebut, dan mengetahui seberapa besar respon siswa terhadap penerapan model pembelajaran kooperatif dengan model Talking Stick. Penelitian ini dilakukan dengan subjek penelitian siswa kelas V SD Negeri I Plawad karawang tahun ajaran 20017/2018. Metode penelitian yang di gunakan adalah metode tindakan kelas (PTK) yang terdiri dari 2 siklus, setiap siklus terdiri dari 2 pertemuan. Pengumpulan data melalui pretest, posttes, observasi, angket, catatan lapangan, dan wawancara. Dari hasil penelitian ini peneliti berharap agar dapat memberikan kontribusi dan manfaat bagi semua pihak-pihak yang terkait, terutama pihak sekolah dalam rangka peningkatan hasil belajar khususunya dibidang pelajaran PAI umumnya bagi pelajaran yang lainnya, sehingga dapat bermanfaat juga bagi sekolah-sekolah lain pada umumnya.
\end{abstract}

Kata Kunci : Model Pembelajaran Talking Stick, Hasil Belajar. 


\section{PENDAHULUAN}

Tujuan pendidikan nasional yang tercantum dalam pasal 3 ayat 1 Undang undang Nomor 20 tahun 2003 tentang Sistem Pendidikan Nasional yaitu : Pendidikan Nasional berfungsi mengembangkan kemampuan dan membentuk watak serta peradaban bangsa yang bermartabat dalam rangka mencerdaskan kehidupan bangsa, bertujuan untuk berkembangnya potensi peserta didik agar menjadi manusia yang beriman dan bertaqwa kepada Tuhan Yang Maha Esa, berakhlak mulia, sehat, berilmu, cakap, kreatif, mandiri, dan menjadi warga negara yang demokratis serta bertanggung jawab. Hal ini menunjukkan bahwa pendidikan merupakan salah satu langkah yang dilakukan untuk membentuk manusia yang beriman dan bertaqwa, serta cerdas dan berkualitas. Sejalan dengan visi pendidikan nasional bahwa dalam era globalisasi dimana manusia dituntut untuk dapat mengikuti perkembangan zaman yang semakin maju, setiap warga negara diharapkan mampu menjadi manusia yang cerdas dan berkualitas.

Untuk mengahsilkan suatu pendidikan yang berkualitas diperlukan seorang guru yang kreatif dan inovatif dalam proses pembelajarannnya dengan menggunakan metode - metode yang membuat siswa aktif dalam proses pembelajarannya, jangan hanya menggunakan metode ceramah yang tidak menuntut siswa untuk aktif dan takut bertanya, Oleh karena itu sesuai hasil Observasi dan wawancara penulis dengan guru SDN I Plawad jika dilihat dari metode yang diguanakan oleh gurunya, hasilnya adalah : (1) guru jarang melakukan apersepsi, (2) masih dominan menggunakan metode ceramah sehingga siswa cenderung pasif, (3) pembelajaran berlangsung dengan suasana yang membosankan dan kurang menarik perhatian, (4) siswa kurang percaya diri dan takut untuk menyampaikan pendapat, banyak siswa tidak dapat menjawab pertanyaan yang diberikan oleh guru. (5) Hasil belajar siswa yang mencapai KKM sekolah masih rendah, yang mana KKM di SDN I Plawad ini 70. Berdasarkan data diatas sehingga peneliti ingin mencoba menggunakan metode kooperatif tipe Talking Stick untuk meningkatkan hasil belajar siswa siswi kelas V SDN I Plawad. 


\section{METODE PENELITIAN1N}

Penelitian penerapan metode pembelajaran kooperatif tipe Talking Stick ini dilaksankan di SD Negeri I Plawad, dengan subjek utamanaya yaitu siswa - siswi kelas V tahun pelajaran 2017/2018 yang terdiri dari siswa laki - laki 12 orang siswi perempuan 13 orang. Metode penelitian ini menggunakan metode penelitian tindakan yang di fokuskan pada situasi kelas, atau lazim dikenal Classroom action research. Penelitian ini dilaksanakan dengan menggunakan desain penelitian tindakan kelas yang terdiri atas beberapa siklus. Masing - masing siklus terdiri dari perencanaan (planning) pelaksanaan tindakan (acting), pengamatan (observing), dan refleksi (reflecting). Instrumen dalam penelitian ini menggunakan lembar soal, LKS, lembar catatan lapangan dan wawancara.

\section{HASIL PENELITIAN DAN PEMBAHASAN}

\section{Siklus 1}

\section{Tabel 1}

Nilai Hasil Belajar Siswa siswi SDN I Plawad Siklus I

\begin{tabular}{|c|c|c|c|c|}
\hline No & NISN & Nama & Pretes & Postes \\
\hline 1 & 0066937227 & Hayah Rosaeni & 60 & 70 \\
\hline 2 & 0071997942 & Dandi Mardiansyah & 70 & 90 \\
\hline 3 & 0088065772 & Zukfan Jaenudin & 50 & 75 \\
\hline 4 & 0096896522 & Wahyuni Khoirunni & 30 & 45 \\
\hline 5 & 0085376931 & Thariq Nurabadillah & 40 & 70 \\
\hline 6 & 00853794561 & Syifa Nursyahidah & 50 & 60 \\
\hline 7 & 0083557771 & Sitihah Nurrahmah & 70 & 70 \\
\hline 8 & 0032000505 & Sera Marlina & 50 & 73 \\
\hline 9 & 0073185283 & Syahrul Andika & 70 & 80 \\
\hline 10 & 0097414748 & Rifanis Sri H & 70 & 70 \\
\hline 11 & 0085137160 & Rizal Fahmi & 60 & 70 \\
\hline 12 & 0073480101 & Raihan Abdul & 65 & 70 \\
\hline 13 & 0075393677 & Rahmawati H & 65 & 75 \\
\hline 14 & 0077164384 & Rifa Handika & 70 & 74 \\
\hline 16 & 0084633908 & Putri Rahayu & 60 & 65 \\
\hline 17 & 0082127846 & Putri Harun Sari & 60 & 75 \\
\hline 18 & 0088726208 & Putri Zahra & 50 & 50 \\
\hline 19 & 0069082085 & Nindhya Seva L & 70 & 70 \\
\hline 20 & 0087624025 & Nala Nimatul M & 70 & 80 \\
\hline 21 & 0086304793 & Nova Aulia Rahma & 75 & 75 \\
\hline 22 & 0082337351 & M darul Qathnu & 60 & 65 \\
\hline 23 & 0088294252 & M Irfan Jauhari & 60 & 70 \\
\hline 24 & 0074906062 & M Irfan Fazar & 60 & 60 \\
\hline 25 & 0072864332 & M Satria Maulana & 55 & 70 \\
\hline \multicolumn{3}{|c|}{ Rata rata } & 57,6 & 66,88 \\
\hline \multicolumn{3}{|c|}{ \% Pencapaian KKM } & $\frac{8}{25} \times 100=33 \%$ & $\frac{16}{25} \times 100=64 \%$ \\
\hline
\end{tabular}


Berdasarkan data siklus I pada pretes nilai rata - rata siswa 57,6 dengan presentai bahwa siswa siswi yang lulus KKM $33 \%$ sedangakan pada pretes nilai siswa siswi rata ratanya 66,8 dengan presentasi siswa siswi yang lulus sebanyak 64 $\%$ berdasarkan data pretes dan postes siswa siswi sudah menunjukan peningkatan nilai baik nilai rata - ratanya atau presentasi nilai KKM yang dilampaui siswa siswi SDN I Plawad, dari nili pretes 33\% dan ketika postes menjadi $64 \%$, dikarenakan masih ada beberapa siswa siswi yang belum melampaui KKM ketika postes yaitu $36 \%$, oleh karena itu peneliti perlu melanjutkan penelitian ini kesiklus II.

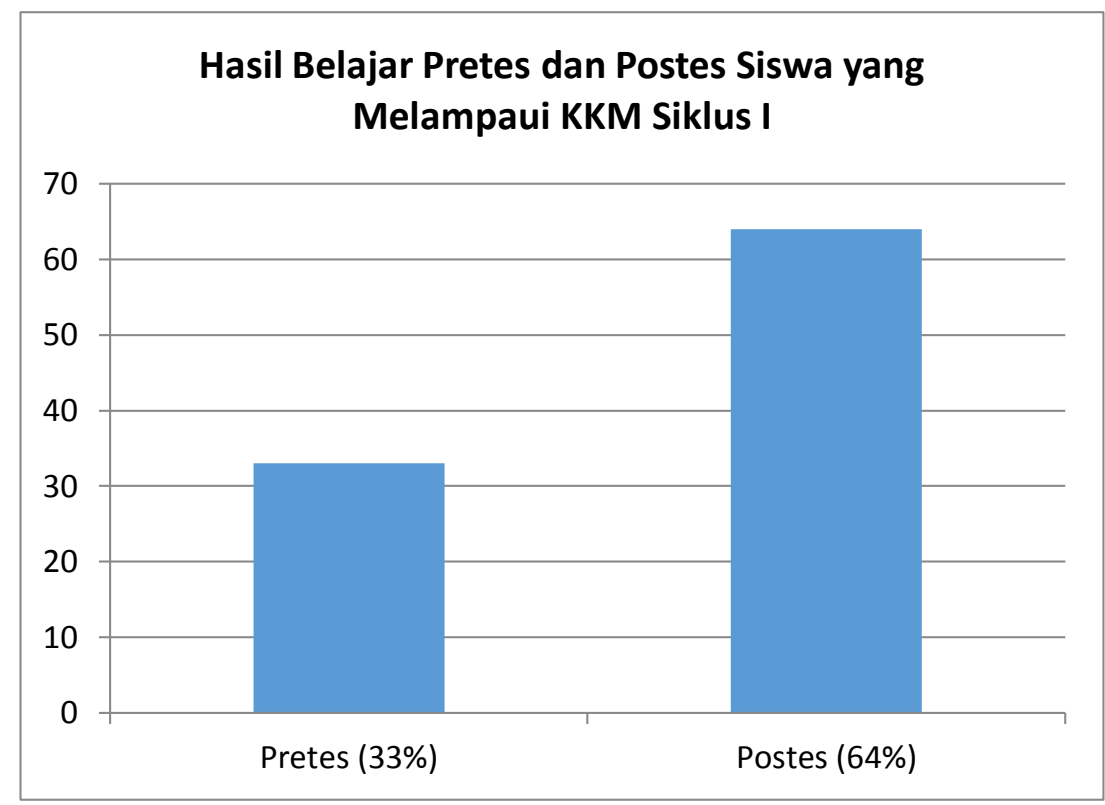

Gambar 1

Hasil Belajar Pre-test Dan Post-Test Siswa Yang Melampaui KKM Siklus I 


\section{Siklus II}

Tabel. 2

Nilai Hasil Belajar Siswa Siswi SDN I Plawad Siklus II

\begin{tabular}{|c|c|c|c|c|}
\hline No & NISN & Nama & Pretes & Postes \\
\hline 1 & 0066937227 & Hayah Rosaeni & 70 & 70 \\
\hline 2 & 0071997942 & Dandi Mardiansyah & 80 & 90 \\
\hline 3 & 0088065772 & Zukfan Jaenudin & 70 & 75 \\
\hline 4 & 0096896522 & Wahyuni Khoirunni & 75 & 85 \\
\hline 5 & 0085376931 & Thariq Nurabadillah & 70 & 70 \\
\hline 6 & 00853794561 & Syifa Nursyahidah & 70 & 75 \\
\hline 7 & 0083557771 & Sitihah Nurrahmah & 60 & 70 \\
\hline 8 & 0032000505 & Sera Marlina & 70 & 73 \\
\hline 9 & 0073185283 & Syahrul Andika & 70 & 80 \\
\hline 10 & 0097414748 & Rifanis Sri H & 70 & 70 \\
\hline 11 & 0085137160 & Rizal Fahmi & 70 & 70 \\
\hline 12 & 0073480101 & Raihan Abdul & 70 & 70 \\
\hline 13 & 0075393677 & Rahmawati H & 70 & 75 \\
\hline 14 & 0077164384 & Rifa Handika & 70 & 74 \\
\hline 16 & 0084633908 & Putri Rahayu & 70 & 70 \\
\hline 17 & 0082127846 & Putri Harun Sari & 72 & 75 \\
\hline 18 & 0088726208 & Putri Zahra & 79 & 90 \\
\hline 19 & 0069082085 & Nindhya Seva L & 75 & 70 \\
\hline 20 & 0087624025 & Nala Nimatul M & 75 & 80 \\
\hline 21 & 0086304793 & Nova Aulia Rahma & 70 & 75 \\
\hline 22 & 0082337351 & M darul Qathnu & 60 & 65 \\
\hline 23 & 0088294252 & M Irfan Jauhari & 65 & 70 \\
\hline 24 & 0074906062 & M Irfan Fazar & 60 & 60 \\
\hline 25 & 0072864332 & M Satria Maulana & 70 & 70 \\
\hline \multicolumn{3}{|c|}{ Rata rata } & 66 & 70,88 \\
\hline \multicolumn{3}{|c|}{ \% Pencapaian KKM } & $\frac{20}{25} X 100=80 \%$ & $\frac{23}{25} \times 100=92 \%$ \\
\hline
\end{tabular}

Berdasarkan data dari siklus II nilai siswa menunjukan peningkatan dari data siklus I, pada pretes nilai rata-ratanya 66 sedngkan presentasi siswa yang melampaui KKM 80\%, dan pada postes nilai rata-rata siswa 70,88 dan presentasi yang melampaui KKM menjadi 92\%. Dikarenakan siswa yang melampaui KKM pada siklus II diatas sudah menunjukan $92 \%$ ini menunjukan peningkatan dari siklus I, dan juga menunjukan bahwa sudah banyak siswa siswi yang melampaui KKM sekitar $92 \%$ berarti presentasi yang belum melampaui KKM 8\%, maka peniliti cukupkan penelitian ini sampai siklus II. 


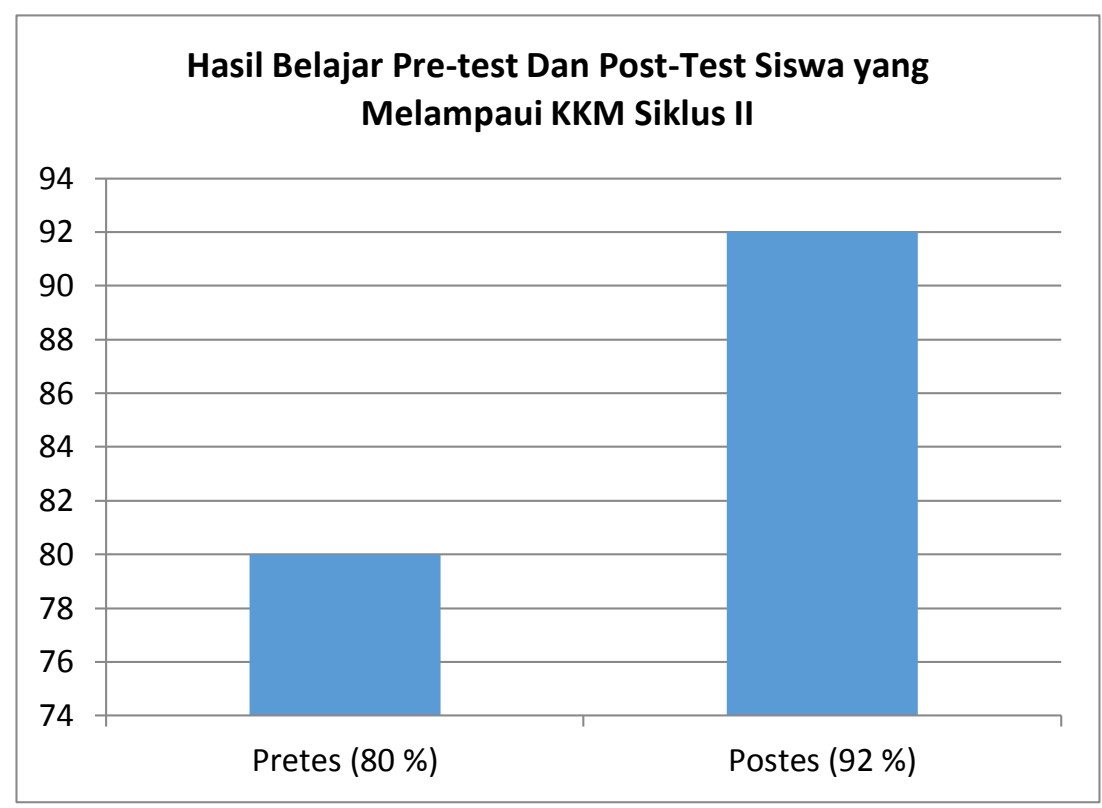

Gambar 2

Hasil Belajar Pre-test Dan Post-Test Siswa Yang

Melampaui KKM Siklus II

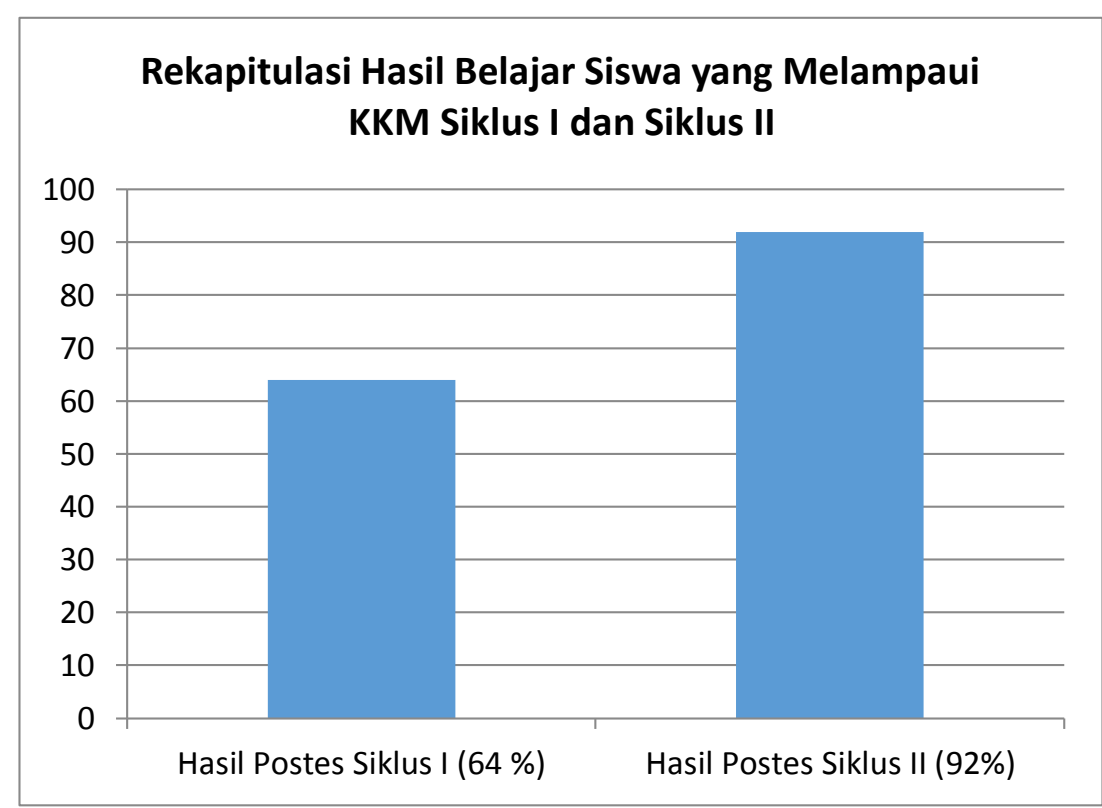

Gambar 2

Rekapitulasi Hasil Belajar Siswa Yang Melampaui

KKM Siklus I dan Siklus II

Berdasarkan data hasil presentasi nilai siswa siswi yang melampaui KKM siklus I dan siklus II diatas, menunjukan bahwa nilai hasil rata - rata siswa siswi SDN I Plawad yang telah melampaui KKM telah menunjukan peningkatan, siklus 
I menunjukan nilai siswa siswi yang melampaui KKM $64 \%$ dengan nilai rata-rata 66,88 sedangkan pada siklus II meningkat menjadi $92 \%$, dengan nilai rata-rata 70,88, peningkatan dari siklus I ke siklus II $28 \%$.

\section{PENUTUP}

Berdasarkan hasil penelitian yang diperoleh, maka dapat ditarik kesimpulan bahwa terdapat peningkatan hasil belajar siswa-siswi yang melampaui KKM yang diajarkan melalui pembelajaran Kooperatif tipe Talking Stick pada materi Pendidikan Agama Islam, ini terbukti dari data yang lulus KKM pada siklus I 64 $\%$,dengan rata - rata 66,88 , lalu pada siklus II terdapat kenaikan menjadi $92 \%$, dengan nialai rata-rata 70,88, presentasi kenaikannya sekitar $28 \%$.

\section{DAFTAR RUJUKAN}

(Ramayulis, Ilmu Pendidikan Islam, (Jakarta, Kalam Mula,2004)

(Hasbullah, Dasar - dasar ilmu pendidikan, (Jakarta: PT Raja Grafindo Persad, 2005)

(Dr Dzakiah Drajat, dkk. Ilmu Pendidikan Islam, (Jakarta; Bumi Aksara.1992)

(Agus Suprijono, Coovratif Learning, (Yogyakarta : Pustaka Pelajar, 2009)

http//tarmiji.wordpress.com/2010/02/15/talking-stick). 
